\title{
SUPPORTING INFORMATION The Catalytic Mechanics of Dynamic Surfaces: Stimulating Methods for Promoting Catalytic Resonance
}

Manish Shetty ${ }^{1,2 \dagger}$, Amber Walton ${ }^{1 \dagger}$, Sallye R. Gathmann ${ }^{1 \dagger}$, M. Alexander Ardagh ${ }^{1,2}$, Joshua Gopeesingh $^{4}$, Joaquin Resasco ${ }^{3}$, Turan Birol ${ }^{1}$, Qi Zhang ${ }^{1}$, Michael Tsapatsis ${ }^{2,6,7}$, Dionisios G. Vlachos ${ }^{2,5}$, Phillip Christopher $^{2,3}$, C. Daniel Frisbie ${ }^{1}$, Omar A. Abdelrahman ${ }^{2,4}$, Paul J. Dauenhauer ${ }^{1,2, *}$

${ }^{1}$ University of Minnesota, Department of Chemical Engineering and Materials Science, 421 Washington Ave. SE, Minneapolis, MN 55455, USA

${ }^{2}$ Catalysis Center for Energy Innovation, 150 Academy Street, Newark, DE 19716, USA

${ }^{3}$ University of California Santa Barbara, Engineering II Building, University of California, Santa Barbara, CA 93106, USA

${ }^{4}$ University of Massachusetts Amherst, 686 N. Pleasant Street, Amherst, MA 01003, USA

${ }^{5}$ University of Delaware, Department of Chemical and Biomolecular Engineering, 150 Academy Street, Newark, DE 19716, USA

${ }^{6}$ Applied Physics Laboratory, Johns Hopkins University, Laurel, MD 20723, USA

${ }^{7}$ Department of Chemical and Biomolecular Engineering \& Institute for NanoBioTechnology, Johns Hopkins University, Baltimore, MD, 21218, USA

* Corresponding author: hauer@umn.edu

$\dagger$ Authors contributed equally

\section{Table \\ 0 Figures \\ 0 Equations}

\section{Table of Contents}

Table S1 Page S2

Photoexcitation experiment Page S3 
Table S1. Turnover efficiency (\%) heatmap data for A-to-B reaction with variable dynamic parameters. Reaction conditions: CSTR operating at $150^{\circ} \mathrm{C}, 100$ bar A feed pressure, and $1 \%$ time-averaged yield of B. Reaction parameters: $\Delta \mathrm{H}_{\mathrm{ov}}$ of $-20 \mathrm{~kJ} / \mathrm{mol}, \alpha$ of $0.8, \beta$ of $102 \mathrm{~kJ} / \mathrm{mol}, \gamma$ of 2.0 , and $\delta$ of $1.4 \mathrm{eV}$. Oscillation amplitude and frequency were varied between $0.1-1.0 \mathrm{eV}$ and $10^{-4}-10^{10} \mathrm{~Hz}$, respectively.

\begin{tabular}{|c|c|c|c|c|c|c|c|c|c|c|c|}
\hline $\begin{array}{c}\text { Freq., } \boldsymbol{f} \\
\left(\boldsymbol{s}^{-\boldsymbol{I}}\right)\end{array}$ & \multicolumn{10}{|c|}{ Amplitude, $\boldsymbol{U}(\mathbf{e V})$} \\
\cline { 2 - 13 } & $\mathbf{0 . 0}$ & $\mathbf{0 . 1}$ & $\mathbf{0 . 2}$ & $\mathbf{0 . 3}$ & $\mathbf{0 . 4}$ & $\mathbf{0 . 5}$ & $\mathbf{0 . 6}$ & $\mathbf{0 . 7}$ & $\mathbf{0 . 8}$ & $\mathbf{0 . 9}$ & $\mathbf{1 . 0}$ \\
\hline $\mathbf{1 E - 0 4}$ & 0.00 & 0.00 & 0.00 & 0.00 & 0.00 & 0.00 & 0.00 & 0.00 & 0.00 & 0.00 & 0.00 \\
\hline $\mathbf{1 E - 0 3}$ & 0.00 & 0.00 & 0.00 & 0.00 & 0.00 & 0.00 & 0.00 & 0.00 & 0.00 & 0.00 & 70.00 \\
\hline $\mathbf{1 E - 0 2}$ & 0.00 & 0.00 & 10.00 & 0.00 & 0.00 & 29.00 & 0.00 & 91.00 & 75.00 & 100.00 & 100.00 \\
\hline $\mathbf{1 E}-01$ & 0.00 & 15.70 & 59.20 & 70.70 & 88.60 & 100.00 & 100.00 & 100.00 & 100.00 & 100.00 & 93.90 \\
\hline $\mathbf{1 E + 0 0}$ & 0.00 & 8.66 & 31.08 & 62.49 & 75.20 & 83.64 & 93.89 & 100.00 & 100.00 & 100.00 & 100.00 \\
\hline $\mathbf{1 E + 0 1}$ & 0.00 & 2.04 & 7.95 & 21.09 & 42.19 & 73.47 & 79.68 & 86.75 & 92.96 & 100.00 & 100.00 \\
\hline $\mathbf{1 E + 0 2}$ & 0.00 & 0.21 & 0.82 & 2.25 & 5.48 & 12.73 & 26.82 & 49.63 & 90.91 & 100.00 & 100.00 \\
\hline $\mathbf{1 E + 0 3}$ & 0.00 & 0.02 & 0.08 & 0.23 & 0.55 & 1.30 & 2.90 & 6.50 & 14.24 & 29.63 & 54.25 \\
\hline $\mathbf{1 E + 0 4}$ & 0.00 & 0.00 & 0.01 & 0.02 & 0.06 & 0.13 & 0.29 & 0.65 & 1.44 & 3.16 & 6.90 \\
\hline $\mathbf{1 E + 0 5}$ & 0.00 & 0.00 & 0.00 & 0.00 & 0.01 & 0.01 & 0.03 & 0.07 & 0.14 & 0.32 & 0.69 \\
\hline $\mathbf{1 E + 0 6}$ & 0.00 & 0.00 & 0.00 & 0.00 & 0.00 & 0.00 & 0.00 & 0.01 & 0.01 & 0.03 & 0.07 \\
\hline $\mathbf{1 E + 0 7}$ & 0.00 & 0.00 & 0.00 & 0.00 & 0.00 & 0.00 & 0.00 & 0.00 & 0.00 & 0.00 & 0.01 \\
\hline $\mathbf{1 E + 0 8}$ & 0.00 & 0.00 & 0.00 & 0.00 & 0.00 & 0.00 & 0.00 & 0.00 & 0.00 & 0.00 & 0.00 \\
\hline $\mathbf{1 E + 0 9}$ & 0.00 & 0.00 & 0.00 & 0.00 & 0.00 & 0.00 & 0.00 & 0.00 & 0.00 & 0.00 & 0.00 \\
\hline $\mathbf{1 E + 1 0}$ & 0.00 & 0.00 & 0.00 & 0.00 & 0.00 & 0.00 & 0.00 & 0.00 & 0.00 & 0.00 & 0.00 \\
\hline
\end{tabular}

The above data is the calculated turnover efficiency for a square waveform operating at $50 \%$ duty cycle, i.e., equal time at each oscillation endpoint. These turnover efficiencies were calculated using equation (5) in the main text. The average steady state TOF was calculated as the arithmetic average of the static TOF at both oscillation endpoints for a given amplitude. For example, averaging the green points shown on Figure 4 gives the average steady state TOF for an amplitude of $0.6 \mathrm{eV}$. 


\section{S2. Photoexcitation Studies.}

For photoexcitation studies, Pt catalysts were synthesized by incipient wetness impregnation on $\alpha-\mathrm{Al}_{2} \mathrm{O}_{3}$ supports at a Pt weight loading of $1.0 \%$. Pt $\left(\mathrm{NH}_{3}\right)_{4}\left(\mathrm{NO}_{3}\right)_{2}$ was used as the platinum source. After drying of the impregnated support, the catalyst was calcined in a tube furnace at $450^{\circ} \mathrm{C}$ for four hours in flowing air to ensure all precursor ligands were removed. Calcined catalysts were then loaded into a Harrick high temperature reaction chamber.

For infrared analysis, a Thermo Scientific Nicolet iS10FTIR spectrometer with a mercury cadmium telluride (MCT) detector cooled by liquid nitrogen was used. Before introduction to the reaction chamber, gases were passed through a liquid nitrogen cold trap and desiccant to remove moisture. The temperature of the reactor bed was calibrated to ensure accurate measurements during temperature programmed desorption experiments. Prior to collecting spectra, catalysts were pretreated in-situ at $250{ }^{\circ} \mathrm{C}$ for one hour in $50 \mathrm{sccm}$ of $10 \% \mathrm{H}_{2} / \mathrm{Ar}$ to ensure platinum was reduced to the metallic state. The catalyst was then cooled to room temperature in $\mathrm{Ar}$ to $25^{\circ} \mathrm{C}$. An infrared spectrum was taken in $\mathrm{Ar}$ at $25^{\circ} \mathrm{C}$ which served as a background for all subsequent scans.

For experiments, carbon monoxide $\mathrm{CO}(10 \%$ in $\mathrm{He})$ or $\mathrm{NO}$ was then passed over the catalyst for 10 minutes until saturation coverage was reached, after which the $\mathrm{CO}$ or $\mathrm{NO}$ was purged from the reaction chamber with argon. Temperature programmed-desorption (TPD) experiments were performed with a ramp rate of $10^{\circ} \mathrm{C} / \mathrm{min}$. The integrated intensity of $\mathrm{CO}$ or $\mathrm{NO}$ stretching features was examined at closely-spaced temperatures. The rate of desorption was obtained as the numerical derivative of the change in intensity as a function of temperature.

The temperature at which the maximal rate of desorption occurred allowed for estimation of the $\mathrm{CO}$ and NO adsorption energy. To do so, the Redhead equation was used, assuming a negligible entropy of activation of desorption. To examine the effect of photoexcitation on $\mathrm{CO}$ and NO binding energies, a 425 $\mathrm{nm}$ LED light source was used (100W LED Chip, 30-34V, 3000mA, CHANZON). Light intensities were calibrated using a thermopile power sensor at the position of the catalyst bed. Light intensities were controlled by adjusting the amperage of the LED power source. 